\title{
Jean-Luc Domenge, Contes merveilleux de Provence et Contes du Diable et de l'Ogre en Provence
}

Josiane Bru

\section{(2) OpenEdition}

\section{Journals}

Édition électronique

URL : https://journals.openedition.org/clo/1239

DOI : $10.4000 /$ clo. 1239

ISSN : 2266-1816

Éditeur

INALCO

\section{Édition imprimée}

Date de publication : 1 janvier 2007

Pagination : 192-194

ISBN : 978-2-85831-174-3

ISSN : 0396-891X

\section{Référence électronique}

Josiane Bru, « Jean-Luc Domenge, Contes merveilleux de Provence et Contes du Diable et de l'Ogre en Provence », Cahiers de littérature orale [En ligne], 62 | 2007, mis en ligne le 16 mars 2013, consulté le 24 juillet 2021. URL : http://journals.openedition.org/clo/1239; DOI : https://doi.org/10.4000/clo.1239

Ce document a été généré automatiquement le 24 juillet 2021.

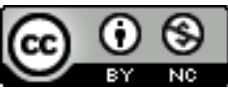

Cahiers de littérature orale est mis à disposition selon les termes de la Licence Creative Commons Attribution - Pas d'Utilisation Commerciale 4.0 International. 


\title{
Jean-Luc Domenge, Contes merveilleux de Provence et Contes du Diable et de l'Ogre en Provence
}

\author{
Josiane Bru
}

\section{RÉFÉRENCE}

Jean-Luc Domenge, Contes merveilleux de Provence et Contes du Diable et de l'Ogre en Provence, Grasse, Éditions TAC Motifs, Collection «Contes et chansons populaires de la Provence », 2003 et 2005, volumes 3 et 4. ISBN : 2-906339-54-7.

1 La recherche d'ouvrages de contes populaires recueillis sur le territoire de l'Hexagone réserve parfois de bien heureuses surprises. Il en est ainsi des deux recueils de contes publiés par Jean-Luc Domenge dans une collection de contes et chants populaires provençaux dont les deux premiers volumes ont été consacrés aux Chants populaires de la Provence, de Damase Arbaud, publiés en 1862 et 1864 et dont la réédition par Chantemerle, en 1972, était devenue introuvable.

2 Les Contes merveilleux de Provence, publiés en 2003 par J. - L. Domenge, proviennent en partie de sa propre collecte, menée dans le Var et les Alpes de Haute Provence entre 1985 et 2000 (quinze versions). Les autres sont issus de sources inédites ou difficilement accessibles : manuscrits, almanachs... Ils sont publiés dans la langue d'origine, avec traduction française pour les textes occitans (dialecte provençal), et présentés autant que possible dans l'ordre de la classification internationale. Leur numérotation, à l'instar du recueil de Jean-Noël Pelen qui signe la préface (Le conte populaire en Cévennes, Paris, Payot, 1994) ou des Contes populaires du Dauphiné de Joisten, permet de repérer les versions d'un même conte. On peut ainsi très naturellement lire à la suite les dix versions de "Jean de l'Ours" (T 301B) ou les quatre versions de "Chaperon rouge " (T 333), et vérifier la rareté du « Corps sans âme » (T 302, une seule version). 
3 Les Contes du Diable et de l'ogre en Provence, parus en 2005, constituent un ouvrage un peu moins volumineux (495 pages au lieu de 615 !) qui regroupe des récits légendaires (cycle des métamorphoses du Drac) dont une bonne part d'étiologies, des contes relevant des autres catégories de l'Aarne-Thompson: plusieurs Contes-nouvelles (deux versions de la « Fille en garçon »...), des Contes de l'Ogre dupé (T 1000, « Les trois Frères à qui on avait coupé les oreilles»), des Contes facétieux (T 1525, T 1641B...) et des Contes religieux chrétiens relevant notamment du cycle du Christ et des apôtres sur terre. L'ouvrage est préfacé par l'historien Philippe Martel, chercheur au CNRS, spécialiste du mouvement félibréen et de ses productions, qui insiste sur les divers partages dont ce livre témoigne : tradition orale et littérature régionale, langue d'oc (dialecte provençal) et langue d'oïl pour la transmission de ces récits.

4 À la fois recueil original et anthologie, chacun des deux volumes, précédés d'une introduction de l'auteur, est remarquable par la précision dont il fait preuve, en particulier dans l'indication de la provenance de chaque version dont il donne la généalogie la plus exacte possible et qu'il situe dans le registre oral ou écrit, transcrit ou remémoré. Après une table de rapprochement avec les contes-types, une bibliographie détaillée des ouvrages de contes provençaux et de recueils de contes des autres pays d'oc contribue à replacer les textes dans leur environnement général et régional.

Plusieurs volumes sont en préparation: des légendes sur les êtres fantastiques, des chants - en commençant par les chants d'amour et de noces, avec la transcription musicale, classés selon le catalogue Coirault - parallèlement au chantier concernant les contes facétieux et autres Beotiana.

6 J.- L. Domenge, enseignant, a fondé le musée des Arts et Traditions populaires de Castellane et publié de nombreux articles sur la langue et la culture populaire provençales. En saluant le remarquable et patient travail du collecteur militant pour la (re)connaissance de sa langue et de sa culture, on rendra hommage au courage de l'éditeur qui, avec le soutien du Conseil Régional Provence Alpes Côte d'Azur, prend en charge le patrimoine oral provençal. Publier des recueils de contes avec texte original et traduction, en juxtaposant plusieurs versions d'un même récit, est de nos jours chose rare, voire impossible dans le cadre national. C'est pourtant une démarche extrêmement précieuse et utile aux conteurs d'aujourd'hui qui, en particulier lorsqu'ils débutent, manquent parfois de repères et abordent de la même façon les versions littéraires des contes, les versions de transmission orale et les réécritures portant la marque de conteurs-auteurs contemporains.

7 Entre tradition orale et écriture, on notera un autre ouvrage du même auteur, publié en 2004 en coédition par Alpes de lumière et la Société scientifique et littéraire des Alpes de Haute Provence : Les papiers de Jean Caire: mémoire, lieux et récits du val d'Allos. J.-L. Domenge a rassemblé des documents que leur auteur n'a pu organiser en un livre de son vivant. Il les éclaire et les complète notamment par des entretiens avec Jean Caire, "un homme fasciné par la parole et par l'écrit» témoignant de la vie et des reconfigurations des rapports humains entre les habitants de la région du Haut Verdon. 